\title{
Comunicação entre usuários e trabalhadores de saúde em colegiados de Saúde da Família
}

\author{
Communication between users and health workers in Family Health committees
}

Comunicación entre usuarios y trabajadores de salud en consejos de Salud de la Familia

\author{
Marcelen Palu Longhi', Priscila Frederico Craco", Pedro Fredemir Palha"' \\ ' Fundação para o Desenvolvimento Médico e Hospitalar, Ambulatório Médico de Espacialidades. Tupã-SP, Brasil. \\ Universidade de São Paulo, Escola de Enfermagem de Ribeirão Preto, \\ Programa de Pós-Graduação Enfermagem em Saúde Pública (Mestranda). Ribeirão Preto-SP, Brasil. \\ "Prefeitura Municipal de Batatais, Programa Saúde da Família. Batatais-SP, Brasil. Universidade de São Paulo, \\ Escola de Enfermagem de Ribeirão Preto, Programa de Pós-Graduação Enfermagem em Saúde \\ Pública (Doutoranda). Ribeirão Preto-SP, Brasil. \\ I'I Universidade de São Paulo, Escola de Enfermagem de Ribeirão Preto, Departamento Materno-Infantil e Saúde Pública, \\ Programa de Pós-Graduação Enfermagem em Saúde Pública. Ribeirão Preto-SP, Brasil.
}

Submissão: 08-09-2011 Aprovação: 19-02-2013

\section{RESUMO}

Atualmente, têm sido observados problemas relativos à comunicação nos fóruns de participação social da saúde. O presente estudo tem o objetivo de analisar a comunicação entre usuários e trabalhadores de saúde, em colegiados da Saúde da Família. O referencial teórico utilizado foi a Teoria da Ação Comunicativa de Habermas. Realizou-se uma pesquisa qualitativa. Os dados coletados revelaram duas dimensões que se entrelaçavam: distanciamentos e aproximações entre usuários e trabalhadores de saúde. Quanto aos distanciamentos, destacaram-se a presença de relações assimétricas, de coerção e de manipulação por parte dos trabalhadores de saúde, processos que prejudicam a participação dos usuários. Por outro lado, estiveram presentes momentos de interação e lutas por direitos, abordados nas aproximações entre usuários e trabalhadores de saúde. Por fim, consideramos que a comunicação nos colegiados da Saúde da Família apresenta potencialidades e limites, sendo que estes devem ser problematizados, especialmente, por meio da educação permanente em saúde.

Descritores: Comunicação em Saúde; Participação Comunitária; Programa Saúde da Família.

\section{ABSTRACT}

Communication problems in social network forums related to health are currently of interest. This study analyzed the communication between users and health workers in the board of Family Health. This is a qualitative study, in which the Habermas' Theory of Communicative Action was the theoretical framework used. Data collected revealed two intertwined dimensions: estrangements and approximations between users and health workers. In relation to estrangements, asymmetrical relationships are highlighted, characterized by coercion and manipulation on the part of the health workers, which are practices that harm the participation of users. On the other hand, moments of interaction and fights for rights addressed during approximations between users and health workers are also present. Finally, we argue that communication in the committees of Family Health present potentialities and limitations and should be discussed, especially through permanent health education.

Key words: Health Communication; Consumer Participation; Family Health Program.

\section{RESUMEN}

Hoy día se observan problemas relacionados a la comunicación en foros de participación social de salud. Este estudio cualitativo objetiva analizar la comunicación entre los usuarios y el personal de salud, en los consejos de Salud de la Familia. El referencial teórico de la Teoría de la Acción Comunicativa de Habermas fue utilizado. Los datos recolectados revelan dos dimensiones que se entrelazan: distanciamiento y acercamiento entre usuarios y trabajadores de salud. Acerca del distanciamiento, se destacan las relaciones asimétricas, de coerción y manipulación realizadas por los trabajadores de salud, procesos que perjudican la participación de los usuarios. Por otro lado, hay momentos de interacción y lucha por los derechos, contenidos en las aproximaciones entre usuarios y trabajadores de salud. Por último, se considera que la comunicación en los consejos de Salud de la Familia tiene potenciales y límites, que deben ser debatidos, especialmente por medio de la educación permanente en salud.

Palabras clave: Comunicación en Salud; Participación Comunitaria; Programa de Salud Familiar.

\section{AUTOR CORRESPONDENTE Marcelen Palu Longhi E-mail: marcelenlonghi@gmail.com}




\section{INTRODUÇÃO}

Vivemos em uma sociedade marcada por iniquidades, na qual grande parte das pessoas é excluída do acesso a bens e serviços de qualidade ou essenciais a sua sobrevivência. O Brasil se destaca, nesse sentido, como um dos países com as piores distribuições de renda do mundo. Associado a este fato, temos presenciado mudanças de cunho sociocultural, tecnológico e econômico, sendo que, de um lado, observa-se que o avanço da tecnologia possibilita melhorias nas condições de vida das pessoas, por outro lado, presencia-se a precarização das relações e condições de trabalho, aumento da violência, dentre outros. Esse quadro tem fomentado o debate sobre direito, democracia e saúde, com revalorização de processos de construção da participação das pessoas na gestão das políticas públicas.

Nesse sentido, a participação social em saúde guarda possibilidades de orientar as políticas públicas, em especial da saúde, no atendimento às necessidades sociais da maioria da população. Conquistas significativas dos movimentos sociais pela saúde, em especial do Movimento da Reforma Sanitária brasileira, tem sido a institucionalização de um sistema nacional de órgãos colegiados, com poderes legais, nos quais usuários têm representação paritária em relação aos prestadores e governo, potencializando o controle sobre as ações da sociedade política.

A constituição dos espaços colegiados na saúde está assegurada por meio de legislação infraconstitucional, Leis Orgânicas da Saúde números 8.080 e 8.142 de 1990 . A Lei ${ }^{\circ}$ 8.142/90 restabeleceu a participação na gestão do Sistema Único de Saúde (SUS), por meio de Conferências e Conselhos de Saúde, sendo o último responsável pela formulação de estratégias e do controle de execução de políticas de saúde ${ }^{(1)}$.

No entanto, apenas o avanço no plano legal e a existência formal dos colegiados não garantem a participação dos sujeitos, pois o processo político nos fóruns da saúde só tem possibilidade de ser efetivo se houver a participação livre e igual de todos os envolvidos. Habermas ${ }^{(2)}$ defende que:

[...] a participação simétrica de todos os membros exige que os discursos conduzidos representativamente sejam porosos e sensíveis aos estímulos, temas e contribuições, informações e argumentos fornecidos por uma esfera pública pluralista, próxima à base, estruturada discursivamente, portanto diluída pelo poder ${ }^{(2)}$.

Estudos envolvendo a comunicação em fóruns da saúde ${ }^{(3-5)}$ apontam para a existência de uma relação assimétrica entre os conselheiros representantes dos usuários e os representantes de outros segmentos, devido à presença de recursos simbólicos e discursivos que afastam, silenciam e excluem os usuários do âmbito das decisões. Longhi ${ }^{6}$ constata a existência de desencontros em colegiados da Saúde da Família, em que, muitas vezes, trabalhadores de saúde desrespeitam, desconsideram e inibem a expressão dos usuários, o que impede sua participação efetiva na construção das políticas relacionadas à sua saúde.

Estudo de caso de duas localidades inglesas ${ }^{(7)}$, com semelhante perfil, estrutura de política nacional e regional na conformação de gerenciamento, mostram divergências entre elas, visto que a localidade em que prevalecia a prática dialógica dos profissionais de saúde com os usuários, constatou-se maior e mais efetivo envolvimento do público nas questões relativas à sua saúde.

O desafio hoje é o de conhecer as dinâmicas interacionais/ comunicacionais dos colegiados, a fim de apontar a existência ou não da comunicação dialógica e, em caso de sua não ocorrência, quais os prejuízos que traz para o processo de participação social( ${ }^{(4)}$. Além do mais, tem sido observada escassez de estudos destinados a avaliar as atitudes dos sujeitos no que diz respeito à gestão dos serviços de saúde em nível local ${ }^{(8)}$.

Como a Estratégia Saúde da Família (ESF) se pauta nos princípios do SUS, em especial no de participação social e vem sendo adotada pelo Ministério da Saúde como política prioritária para a reorganização da Atenção Básica, tal fato nos remete à importância de compreender o processo de comunicação em seus colegiados. A Saúde da Família pode ser considerada como um local favorável para o exercício da democracia e da participação social, sendo vislumbrada diante da possibilidade de os sujeitos exercerem o papel de protagonistas na construção e organização do sistema local de saúde.

Assim, este estudo tem como objetivo analisar a comunicação em colegiados da ESF, buscando compreender a participação de seus membros e identificando seus limites e potencialidades.

\section{A Teoria da Ação Comunicativa nos fóruns da saúde}

Como pretendemos estudar a comunicação entre trabaIhadores e usuários em colegiados de Saúde da Família, nos aproximamos da Teoria da Ação Comunicativa de Jürgen Habermas, que nos oferece elementos para compreender as falas e as relações subjetivas, entre os sujeitos sociais em interação.

Habermas critica a predominância da razão instrumental na modernidade, marcada pelo domínio da ciência e da técnica que agem como "dificultadoras" da emancipação humana, e constrói a Teoria da Ação Comunicativa, a fim de imprimir uma nova relação entre os sujeitos. Em sua teoria, Habermas $^{(9)}$ diferencia a Ação Comunicativa das ações orientadas ao êxito (ação estratégica e instrumental). O êxito é entendido pelo autor como a execução de um estado de coisas desejadas, causado mediante ação ou omissão calculadas, sendo uma ação orientada a um fim, em que se busca alcançar uma meta, sem considerar a perspectiva do outro.

A Ação Comunicativa se pauta no entendimento linguístico entre os sujeitos, amparando-se no paradigma comunicativo que supera o paradigma da consciência, ao avançar da relação do sujeito solitário com o objeto a sua volta, para a relação intersubjetiva de pessoas que buscam o entendimento entre $\mathrm{si}^{(9)}$. Nesse sentido, o agir comunicativo é concebido por Habermas como uma forma de abrir possibilidades para um entendimento em sentido abrangente, não restritivo ${ }^{(10)}$.

$\mathrm{Na}$ Teoria da Ação Comunicativa, Habermas ${ }^{(9)}$ procura reconstruir as condições universais dos atos de fala ou proferimentos linguísticos, vistos como uma ação linguística por meio da qual um falante gostaria de chegar a um entendimento com outro interlocutor sobre algo no mundo e considera que os atos 
de fala possuem pretensões de validade, o que significa que podem ser questionados, com base em argumentos, ou seja, podem ser fundamentados. Na busca de entendimento consensual, estas pretensões devem-se sobrepor às de poder ${ }^{(11)}$.

Dessa forma, em cada ato de fala, devem estar presentes quatro pretensões ou expectativas de validade: a pretensão de verdade proposicional ou verdade da afirmação; a pretensão de retitude ou correção normativa; a pretensão de veracidade ou autenticidade expressiva; e a pretensão de inteligibilidade. A pretensão de verdade proposicional ou verdade da afirmação pode ser representada pelos "atos de fala constatativos ou afirmativos" em que a expectativa é que os conteúdos proposicionais sejam verdadeiros. A pretensão de retitude ou correção normativa pode ser expressa pelos "atos de fala regulativos" que, para serem aceitos, devem estar de acordo com as normas sociais vigentes, respeitando o ponto de vista ético, moral e político. A pretensão de veracidade ou autenticidade expressiva engloba os "atos de fala representativos ou expressivos" e refere-se à subjetividade dos interlocutores, à sua transparência e sinceridade; assim, espera-se que o falante seja sincero consigo mesmo e com os outros ${ }^{(12)}$. A pretensão de inteligibilidade trata da expectativa de que os conteúdos transmitidos sejam compreensíveis.

As três primeiras pretensões de validade dos atos de fala se entrelaçam com as relações sujeitos-mundo ${ }^{(9)}$, desse modo, a pretensão de verdade proposicional se relaciona a um mundo objetivo, ou seja, à totalidade dos fatos cuja existência pode ser verificada. A pretensão de retitude está ligada ao mundo social dos atores, entendido como a totalidade das relações interpessoais e legitimamente reguladas. Já a pretensão de veracidade está relacionada a um mundo subjetivo, compreendido com a totalidade das experiências, a que cada sujeito tem acesso privilegiado, e o falante pode manifestar-se em público.

No entanto, as pretensões de validade podem não ser cumpridas, já que são pretensões ideais e não factuais; e porque muitas formas de comunicação não se regem de fato pelas pretensões anunciadas. Especialmente, nas formas estratégicas de comunicação há uma suspensão das mesmas. A mentira e a manipulação destroem a confiança na veracidade do que é dito, dessa forma, quem age estrategicamente se nega a comunicar-se validamente.

No contexto da Teoria da Ação Comunicativa, a fim de compreender o processo histórico da sociedade, Habermas ${ }^{(9)}$ utiliza os conceitos de mundo da vida e de mundo sistêmico. O mundo da vida é concebido como a composição das convicções culturais, da ordem institucional e da estrutura da personalidade, dessa forma, cultura, sociedade e personalidade representam os processos de reprodução cultural, de integração social e de socialização. No mundo da vida, prevalecem as vivências e experiências partilhadas pelos sujeitos, no cotidiano vivido, sendo que os homens buscam o entendimento e consenso por meio da comunicação ${ }^{(12)}$.

O mundo sistêmico ou sistema compreende a esfera social desconectada do mundo da vida, no qual as ações não são orientadas para o entendimento linguístico, mas regidas por mecanismos de regulação alinguísticos, representados pelo dinheiro e o poder. Este mundo é caracterizado pela predominância da razão instrumental e técnica, sendo que a interação entre os sujeitos fica prejudicada.

E o processo social caracterizado pela crescente racionalização do mundo da vida é denominado de colonização do mundo da vida, no qual os meios deslinguistizados (dinheiro, mercado e poder) se sobrepõem cada vez mais ao mundo da vida, aos processos comunicativos mediados linguisticamente. Dessa forma, os imperativos sistêmicos, as pretensões de poder impõem-se sobre as pretensões de validade, causando uma série de patologias, de perturbações da interação social que atingem as sociedades capitalistas contemporâneas.

Para Habermas, deve existir certo equilíbrio entre os dois mundos, o mundo da vida e o mundo sistêmico, assim, torna-se necessário que a razão instrumental seja recolocada em seu espaço ${ }^{(2)}$. Esse processo é denominado de descolonização do mundo da vida.

Consideramos que, na perspectiva da Teoria da Ação Comunicativa, nos fóruns da ESF, a concretude da participação seria permeada por um acordo intersubjetivo, pautado nos princípios de sinceridade (veracidade), de verdade, de concordância com as normas sociais (retitude) e de compreensão do que está sendo dito. Desse modo, todos os sujeitos participantes teriam o direito de falar e serem ouvidos, discutir sobre o que está sendo falado e participar das decisões consensuais. Entendemos a privação da fala de sujeitos, ou grupo deles, por outros, nos colegiados da ESF, como modelos distorcidos de comunicação que se distanciam da proposta da Ação Comunicativa.

A proposta da ESF corrobora a perspectiva da Ação Comunicativa, já que a Saúde da Família deve se basear nos princípios do SUS e buscar transformar o modelo assistencial de saúde, centrado no profissional médico, na instituição hospitalar e na cura de doenças, em um modelo que atenda às reais necessidades de saúde da sociedade, considerando o sujeito em sua integralidade. No entanto, no cotidiano dos serviços de saúde, muitas vezes, tem prevalecido um cuidado prescritivo e autoritário que se distancia dos seus pressupostos. Contudo, somente a mudança da estrutura, dos recursos em jogos e seus formatos não transformam por consequência os modelos assistenciais e suas políticas instituintes ${ }^{(13)}$. Esses autores defendem a ideia de que a construção um novo modelo assistencial exige a formação de uma nova subjetividade entre os trabalhadores, que ultrapasse os saberes técnicos empregados na produção de saúde, e que se oriente pelas diretrizes do acolhimento, vínculo/responsabilização e autonomização.

\section{METODOLOGIA}

Para analisarmos a comunicação entre os sujeitos, realizamos uma pesquisa de abordagem qualitativa, em colegiados designados como reuniões de comunidade com trabalhadores da Saúde da Família, em uma unidade de saúde (USF), num município do interior paulista. Esse município possui uma população de 200 mil habitantes, tendo uma cobertura de, aproximadamente, $35 \%$ da ESF, sendo superior à média estadual que é de $23 \%$. Para escolha da USF cenário do estudo, selecionamos aquela que, dentre as 28 existentes, apresentou nos anos anteriores ao estudo, 2006 e 2007, uma participação 
mais expressiva em seu colegiado, considerando como critérios de inclusão, o maior número de reuniões realizadas e de participantes por encontro. As reuniões de comunidade com trabalhadores da Saúde da Família, adotadas como espaço de participação social na ESF por esse município, diferem das reuniões dos Conselhos de Saúde, pela não existência de cargos e funções e por serem constituídos exclusivamente por usuários e trabalhadores de saúde.

Para a coleta de dados, utilizamos a observação participante das reuniões mensais, durante os meses de março a agosto de 2008, totalizando cinco observações; a entrevista semiestruturada com os participantes que apresentaram frequência significativa no ano anterior, sendo 6 trabalhadores e 8 usuários, 14 entrevistas no total; e a análise documental de atas de tais reuniões e dos relatórios de gestão da Secretaria Municipal de Saúde. A entrevista semiestruturada englobava questões referentes aos horizontes vida, família, trabalho, participação e comunicação.

Empregou-se a análise de conteúdo, modalidade temática, para a interpretação do material empírico, sendo que, nas entrevistas semiestruturadas, foram privilegiadas as falas referentes aos horizontes participação e comunicação. Durante a análise dos dados, ênfase foi dada as pretensões/ horizontes normativos (que pertencem ao mundo social) presentes nos proferimentos linguísticos dos sujeitos.

Os princípios éticos que norteiam a pesquisa pautam-se na Resolução 196 do Conselho Nacional de Saúde (CNS), tendo sido aprovada pelo Comitê de Ética em Pesquisa da Faculdade de Medicina de Marília, sob processo $\mathrm{n}^{\circ}$ 1.348/07 e pela Secretaria de Saúde do município de realização da pesquisa. A coleta de dados foi realizada com a anuência dos sujeitos, mediante apresentação de Termo de Consentimento.

\section{RESULTADOS E DISCUSSÃO}

Em nossa análise, os atos de fala acerca das reuniões nos levaram a trilhar dois caminhos que se mesclavam: um pautado no princípio de participação do SUS e da Ação Comunicativa e outro orientado pela dominação e desrespeito aos usuários. Portanto, construímos duas categorias para analisar a participação em fóruns de discussão na Saúde da Família: distanciamentos e aproximações, entre usuários e trabalhadores de saúde. No contexto dos distanciamentos, construímos as seguintes dimensões: o usuário calado e o "fardo" da participação; e no contexto das aproximações: interação entre os sujeitos e espaços de discussão dos problemas locais.

Destacamos que, neste artigo, as categorias estão delimitadas separadamente apenas para fins didáticos e operacionais, guiando a condução da interpretação dos dados.

\section{A. Distanciamento entre usuários e trabalhadores de saúde}

\section{O usuário calado}

A análise dos dados evidenciou entraves, distorções e desencontros em espaços de participação da Saúde da Família. Um aspecto que ressaltou em nosso estudo foi o silenciamento dos usuários diante dos trabalhadores de saúde nos colegiados. Durante a observação foi constatado que os usuários permaneciam, a maior parte do tempo, calados, o que também foi apontado pelo pessoal da saúde.

Denominamos este momento de "usuário calado" em referência oposta à proposição do "usuário centrado", em que o processo de cuidado se centra nas necessidades deste, de modo integral e ampliado. Assim, o usuário calado reflete o processo de distanciamento entre os sujeitos nesses espaços de discussão. Em conversa com os usuários e mesmo nas observações de reuniões, visualizamos muitos aspectos que contribuem para esta postura do usuário, com destaque para as relações assimétricas de saber e poder entre trabalhadores e usuários.

As relações assimétricas de saber e poder entre trabalhadores de saúde e usuários, caracterizadas pelo uso do poder e/ ou saber pelos primeiros como forma de dominação e opressão, são práticas que historicamente têm predominado nas relações entre esses sujeitos, especialmente, nos serviços de saúde, e se refletem nos colegiados.

No fórum estudado, muitas das assimetrias presentes estão intimamente relacionadas à diferenciação de "saberes", sendo que, muitas vezes, os trabalhadores de saúde se mostram como detentores do conhecimento cientificamente "válido", geralmente expresso pelo domínio da linguagem técnica e codificada (com códigos). Os usuários que, por sua vez, não são familiarizados com esse tipo de conhecimento e uso da língua, referem que possuem uma linguagem simples:

[...] é tudo, como eu vou dizer, meio quieto, meio simplão, ninguém quer falar nada, pode ver que quando pergunta, fica tudo simples... ninguém quer responder nada [...] a turma do posto eles já explicam tudo certinho pra pessoa, mas se for só o povo mesmo! (U1- Usuário 1)

O conhecimento científico passou a ser divulgado como verdade, dogma, desvalorizando-se o senso comum e o saber popular. A linguagem técnica/codificada se mostra como um desencontro comunicacional na Saúde da Família, sendo que, nos serviços de saúde, as interações são mediadas por uma linguagem técnica e nas experiências cotidianas dos usuários está presente uma linguagem prática, relacionada ao mundo da vida, o que faz emergir barreiras na comunicação e interação dos sujeitos ${ }^{(12)}$.

Atualmente, de acordo com Habermas, as decisões práticas de ordem coletiva são transformadas em problemas técnicos, devendo ser resolvidos por uma minoria de experts que tem o Know-how necessário, o que leva a uma despolitização das massas. Essa, por sua vez, passa a ser consequência e requisito da dominação da racionalidade técnica. Assim a redução das decisões políticas de uma minoria (tecnocrata) leva ao esvaziamento da atividade prática nas instâncias política, social e econômica(14).

Aliadas aos imperativos de saberes, as comunicações no fórum estudado são permeadas por relações de poder, construídas socialmente, marcadas pela coerção, que, geralmente, colocam os usuários em uma posição inferiorizada, o que contribui para que permaneçam calados. Essas relações 
assimétricas se intensificam entre os profissionais graduados (médico, dentista e enfermeiro) e usuários, já que os primeiros têm a possibilidade de vetar os atendimentos individuais, como revela a seguinte fala:

[...] quando não veio ninguém do nível superior, parece que a comunidade ficou mais à vontade, que não veio o nível superior e eles parecem que falaram mais, não sei se às vezes eles ficam com receio "ah se eu falar tal coisa ela não vai me atender mais", né? (T1- Trabalhadora 1)

A relação apontada acima revela um desvio, uma distorção na comunicação, na qual o poder simbólico dos trabalhadores de saúde é empregado para controlar a ação dos usuários, para que atenda aos seus fins, as suas vontades e pretensões. Como pano de fundo, aqui se mostra uma concepção restrita de saúde que não é vista como um direito social dos sujeitos.

\section{O "fardo" da participação}

Em nosso estudo, predominaram sentimentos negativos em relação à participação nos colegiados, tanto por parte dos trabalhadores de saúde como pelos usuários. A participação em tais espaços foi relatada como um "fardo", por um sujeito entrevistado, revelando o "peso", dificuldades e insatisfações no ato de participar.

Percebemos que essas impressões se relacionam aos elementos anteriormente expostos e, especialmente, à manipulação dos sujeitos por meio da linguagem. A manipulação, nos fóruns da ESF, esteve relacionada ao estabelecimento de condicionalidades na frequência tanto dos usuários quanto dos trabalhadores de saúde.

A manipulação dos sujeitos por meio da linguagem ocorre quando as pessoas são tratadas como objetos, já que apenas os objetos são suscetíveis a manejo/manipulação. Aqueles que manipulam pretendem que suas propostas sejam aceitas sem oferecer razões para as mesmas, não respeitam a liberdade alheia, e conduzem as pessoas a agir de acordo com seus propósitos.

Nossa pesquisa evidenciou distanciamentos comunicacionais, permeados pela manipulação dos sujeitos por meio da linguagem, especialmente, quando trabalhadores de saúde condicionam a presença/frequência dos usuários na reunião do colegiado ao acesso ao Programa Bolsa Família (PBF). No entanto, não há regulamentação legal que condicione o recebimento do auxílio à participação nas reuniões, apesar de existirem outras condicionalidades aos beneficiários do PBF. Os profissionais de saúde revelaram que essa foi uma estratégia encontrada para aumentar a frequência dos usuários ao colegiado:

Foi pensado, como eu posso dizer, foi de propósito, ó como não vem ninguém na reunião de comunidade, quem sabe se a gente falar para elas que é obrigatório, pra elas irem. (T2-Trabalhadora 2)

Essa situação nos remete a um modelo conturbado de comunicação que não se pauta no entendimento intersubjetivo, mas que se orienta para atingir um propósito, sem considerar as vontades dos sujeitos. Assim, não são considerados os desejos, as perspectivas e as possibilidades das pessoas, em relação ao acesso, disponibilidade de horário, mesmo que os encontros ocorram durante a noite.

A manipulação dos usuários fica explícita, quando olhamos para os sujeitos que mais frequentam esses espaços: todos são beneficiários do PBF e, inclusive, como a assiduidade da frequência foi um parâmetro para nossas entrevistas, não por coincidência, todos os entrevistados pertenciam ao referido programa. Poderia até se pensar que a maioria das famílias adstritas dessa unidade de saúde estaria vinculada ao PBF, no entanto, por volta de $5 \%$ delas são cadastradas nesse programa de transferência de renda.

Assim, por vezes, para que esses usuários continuem frequentando esse espaço, os trabalhadores lançam mão de um discurso ameaçador que desperta medo, o medo da interrupção ou bloqueio do auxílio, o que pode ser explicitado pela fala:

A população também vai por causa do (Programa) Bolsa Família, vai por medo de perder a bolsa. (T3-Trabalhadora 3)

O medo se torna uma ferramenta eficaz, em vários casos, pois muitas pessoas que participam desses espaços dependem dos recursos do PBF para sua sobrevivência, devido às suas precárias condições financeiras.

Os desencontros de horizontes geram conflitos de práticas em tais espaços, sendo que, muitas vezes, os trabalhadores não se mostram abertos a discutir os pontos de vista dos usuários e acabam impondo suas expectativas. No entanto, os trabalhadores revelam que não receberam nenhum tipo de capacitação para conduzir os colegiados e que enfrentam muitas dificuldades na relação com a população. $O$ que nos faz pensar na formação restrita dos profissionais da área da saúde, centrada especialmente nos procedimentos técnicos, e assim, no processo dialético da participação, esses sujeitos se mostram vulneráveis.

Além dos usuários, os próprios trabalhadores também são condicionados a participar do fórum, como uma exigência de sua função. E assim, se repete a situação anterior, no entanto, diferentemente do caso dos usuários, essa regra possui validade legal. Mas não deixa de ser impositiva, sendo que muitos trabalhadores referem insatisfação ao frequentar o colegiado:

Eu não vou porque eu gosto, se eu falar isso eu tô mentindo. Eu vou porque a gente tem que ir. Eu vou porque sou obrigada, porque eu trabalho aqui no posto. (T3-Trabalhadora 3)

Isso revela a manipulação também dos trabalhadores, já que sua frequência nesses espaços, muitas vezes, não tem sido espontânea, o que está relacionado a uma forma vertical de comunicação. A verticalização da comunicação se inicia com a imposição da participação dos trabalhadores, pelos gestores municipais e, sequencialmente, com a imposição da participação dos usuários pelos trabalhadores. Na comunicação hierarquizada, não se respeitam as vontades dos sujeitos, as decisões são tomadas pelos dirigentes e repassadas aos "subordinados", que muitas vezes, não as acatam, apenas desempenham as ordens formalmente. 
Os achados de nosso material empírico, até o momento, nos mostram problemas, falhas, desencontros/distanciamentos no processo comunicacional entre trabalhadores e usuários, revelando uma situação de colonização dos espaços de participação, sendo que nesses espaços deve prevalecer a racionalidade presente no mundo da vida.

A colonização dos espaços relativos ao mundo da vida nos remete a pensar no agir comunicativo como força integradora entre os sujeitos, que precisa ser construída e reconstruída, nas esferas de interação intersubjetiva que foram invadidas por outras racionalidades, como a burocrática e econômica, que não são adequadas e por isso levam à perda de liberdade e sentido ${ }^{(10)}$.

\section{B. Aproximações entre usuários e trabalhadores de saúde}

Os espaços de discussão na saúde se configuram como dinâmicos e contraditórios, sendo que a comunicação estabelecida, ora propicia a participação dos sujeitos nas decisões, ora inibe esse processo, se configurando como excludente.

Já discutimos acerca dos momentos em que a interação entre os sujeitos estava prejudicada e influenciava negativamente sua participação. Aqui procuraremos evidenciar elementos que têm contribuído/potencializado a participação dos usuários, por meio do processo comunicativo, como a interação entre os sujeitos e os espaços de discussões de problemas locais.

\section{A interação entre os sujeitos}

A pesquisa também apontou momentos de aproximações nos fóruns da ESF, marcados pela interação dialógica entre trabalhadores e usuários que foram revelados por meio da importância designada à participação de trabalhadores da saúde.

A importância designada à participação de trabalhadores da saúde, nas reuniões, foi relatada por usuários, que demonstraram afetos, por exemplo, pela dentista e enfermeira.

Eu acho importante, eu acho legal a participação do pessoal do posto. E fazia tempo que eu não via a enfermeira [...] Aí eu fiquei contente de ver ela ali, eu gosto, eu acho legal. Ah eu gosto muito dela desde o começinho que ela tá aqui, eu gosto muito dela então [...](U2-Usuário2)

Às vezes tem a dentista, eu adoro a dentista ela me fez perder o medo de dentista, eu gosto quando ela tá lá. Eu gosto desse postinho de saúde [...](U3-Usuário 3)

Como se pode notar, nas reuniões, os usuários revelam-se satisfeitos com a presença das trabalhadoras de saúde pelas quais sentem afetividade, o que indica que o vínculo/fusão de horizontes, construído nas atividades cotidianas do serviço de saúde, acaba por aproximar o usuário dos espaços de participação. E denotam a importância da construção de vínculos que favorecem tanto o cuidado como a participação dos sujeitos, o que vai de encontro aos princípios da ESF.

Em nosso estudo também foi ressaltada a relevância da participação do Agente Comunitário de Saúde (ACS) nas reuniões, como potencializadora da participação do usuário e também dos demais trabalhadores. Vários trabalhadores alegam que os usuários sentem-se mais à vontade e participam ativamente quando os ACS estão presentes, devido à relação de proximidade entre eles. Os usuários geralmente expõem seus problemas/necessidades para seu próprio ACS, que já conhece sua realidade e tem mais condição de ajudá-lo, auxiliá-lo, guiá-lo em seu enfrentamento. E, além de permitir maior interação e participação dos usuários, gera segurança para os demais trabalhadores, que em alguns casos, não teriam elementos suficientes para responder às demandas dos usuários como faria seu agente comunitário.

Dessa forma, nos colegiados há "encontros" de usuários com trabalhadores, sejam eles os Agentes Comunitários de Saúde (ACSs) que potencializam sua participação ou com aqueles que possuem afinidades. Esses encontros seguem o caminho da ação comunicativa, afinal, estão permeados pelo entendimento entre os sujeitos em interação que se respeitam mutuamente e constroem laços de amizade e confiança.

As relações a serem estabelecidas nos fóruns da saúde devem se aproximar do mundo da vida, visto que a comunicação deve ser orientada ao entendimento entre os sujeitos, por meio dos planos de validação dos processos comunicacionais, da correção normativa, da verdade proposicional e da autenticidade expressiva, propostos por Habermas, segundo o qual, há possibilidade de os sujeitos construírem um diálogo positivo ${ }^{(16)}$.

\section{Espaço de discussão dos problemas locais}

Em diversos momentos deste estudo, presenciamos ações de planejamento em saúde. O planejamento desenvolvido nos fóruns estudados se pauta nos princípios do planejamento estratégico situacional, que é composto pelos momentos explicativo, operacional, estratégico e tático-operacional. Dentre as várias modalidades de planejamento estratégico situacional, desenvolveram-se momentos do Método Altadir de Planejamento Popular (MAPP) que se caracteriza por ser participativo, pois considera a visão das pessoas acerca de seus problemas, estimulando o compromisso dos sujeitos com as ações para enfrentamento dos mesmos, pela promoção de descentralização, democratização e distribuição de poder.

No entanto, autores apontam contrastes entre a lógica da racionalidade do planejamento estratégico e do agir comunicativo, sendo que os atores que conduzem o planejamento se distanciam comunicativamente daqueles que vivenciam os problemas ${ }^{17}$. Mas consideram que o planejamento estratégico, por pautar-se no diálogo, pode se aproximar do planejamento comunicativo, desde que abra possibilidade para uma problematização coletiva, que articule os sujeitos sociais e incorpore um raciocínio sobre a governabilidade de situações de compartilhamento e dispersão do poder que enfatiza a negociação política.

Os autores acima referidos consideram que, mesmo que o planejamento estratégico não coloque explicitamente sua perspectiva comunicativa, o reconhecimento do ato de planejar como relação interativa, o estabelecimento da negociação cooperativa como meio estratégico, a valorização da explicação do outro como parâmetro de crítica da nossa própria explicação e a relevância concedida à cultura no delineamento das regras institucionais são elementos que possibilitam uma compreensão do planejamento como não orientado somente para atingir certos fins. 
Em vários momentos da realização do MAPP, observamos situações que se aproximam da lógica do planejamento estratégico, em sua perspectiva comunicativa, como discutida anteriormente. Nesses momentos esteve presentes o desenvolvimento de práticas democráticas de ações de enfrentamento de problemas comunitários.

O desenvolvimento de práticas democráticas de ações de enfrentamento de problemas comunitários, como o levantamento, escolhas de problemas e explicações de suas causas, realizou-se durante duas reuniões observadas. Nessas reuniões, os trabalhadores de forma inclusiva solicitaram aos usuários que elencassem os problemas mais relevantes de acordo com sua perspectiva:

[...] porque a gente tá fazendo o levantamento de problemas, pra gente poder planejar estratégias de alguma coisa que esteja incomodando vocês, né [...] O maior problema que vocês consideram na comunidade [...] (T2-Trabalhadora 2)

Apesar da falta de continuidade no desenvolvimento dos momentos do planejamento, em encontros subsequentes, após novo levantamento dos problemas, foram esclarecidos aos usuários, em linguagem clara e compreensível, os momentos que compõem o MAPP. Após a conclusão da seleção do problema, por votação coletiva, passou-se para a explicação das causas e consequências do mesmo. E criativamente, os trabalhadores instigaram os usuários, para que falassem acerca das causas do problema e sua repercussão, revelando mais uma vez que o usuário permanece calado, quando não encontra espaço para falar, já que participaram ativamente desse processo. Foi possível observar o desenvolvimento do planejamento até o momento explicativo e inicio do momento operacional, devido ao encerramento das observações participantes.

Os elementos discutidos, no segundo momento deste artigo, se aproximam do processo de Descolonização do Mundo da Vida, que só pode ocorrer quando recuperarmos a nossa capacidade de comunicação, implementando transparência, flexibilidade e dirigibilidade nas nossas ações. Habermas acredita na competência das pessoas e que elas são capazes de produzir a ação comunicativa, por meio do diálogo, com possibilidade de transformar a realidade existente ${ }^{(12)}$.

\section{CONSIDERAÇÕES FINAIS}

A construção dos dados nos revela caminhos tortuosos do uso da linguagem que contribuem tanto para oprimir como para emancipar os sujeitos. A análise nos permite visualizar fóruns de Saúde da Família como espaços dinâmicos e contraditórios, constituídos tanto por momentos marcados por alteridade, confiança, amizade, respeito, sinceridade entre os sujeitos, visando a ampliar os horizontes participativos, bem como por situações caracterizadas pela dominação, manipulação, coerção e desrespeito que desvirtuam as relações na ESF.

Assim, consideramos que os momentos de desencontros/ distanciamentos, muito frequentes nos fóruns estudados, precisam ser "estranhados", questionados, refletidos com vista a sua descolonização do mundo da vida/espaços de participação. Caminhos possíveis para enfrentar esses problemas incluem a construção e ampliação de momentos/espaços de diálogos entre trabalhadores e destes com usuários e educação e, especialmente, a formação de trabalhadores de saúde, baseada na educação permanente.

Ceccim e Feuerwerker ${ }^{(18)}$ identificam a participação/controle social como uma das faces essenciais da formação em saúde, ao construir o conceito de quadrilátero da formação que engloba também o ensino, a gestão e a atenção. Assim, o quadrilátero da formação, ou seja, ensino, gestão setorial, práticas de atenção e participação/controle social, propõe a construção de uma educação amparada por processos interativos e de ação na realidade, para operar mudanças, mobilizar caminhos, convocar protagonismos e criar novos cenários de conhecimentos e invenções. Nesse sentido, a participação social, interligada às outras faces do quadrilátero (ensino, gestão e atenção), deve atravessar todo o processo de formação e capacitação na área da saúde, com vistas a proporcionar uma formação crítica, humanizada e problematizadora da realidade.

Por um fim provisório, consideramos que os colegiados da Saúde da Família carregam potencialidades que precisam ser ampliadas para se reconstruir um modelo de comunicação que permita a participação dos sujeitos e sua participação nas políticas sociais, sendo necessário que a lógica comunicativa ultrapasse esses espaços e permeie todo o processo de trabaIho nos serviços de saúde.

\section{REFERÊNCIAS}

1. Brasil. Lei $n^{\circ} 8.142$, de 28 de dezembro de 1990. Dispõe sobre a participação da comunidade na gestão do Sistema Único de Saúde - SUS e sobre as transferências intergovernamentais de recursos financeiros na área da saúde e dá outras providências. Diário Oficial da União 31 dez 1990; Secão 1.

2. Habermas J. Direito e democracia: entre faticidade e validade. Rio de Janeiro: Tempo Brasileiro; 1997.

3. Serapioni $\mathbf{M}$, Romani O. Potencialidades e desafios da participação em instâncias colegiadas do sistema de saúde: os casos de Itália, Inglaterra e Brasil. Cad Saúde Pública 2006;22(11):2411-2421.

4. Oliveira VC. Comunicação, informação e participação popular nos conselhos de saúde. Saúde Soc 2004;13(2):56-69.

5. Wendhausen A, Caponi S. O diálogo e a participação em um conselho de saúde em Santa Catarina, Brasil. Cad Saúde Pública 2002;18(6):1621-1628.

6. Longhi MP. Participação social: a comunicação que aproxima e distancia usuários e trabalhadores da Saúde da 
Família. Ribeirão Preto. Dissertação [Mestrado em Enfermagem] -Escola de Enfermagem de Ribeirão Preto da Universidade de São Paulo; 2009.

7. Callaghan G, Wistow G. Governance and public involvement in the British National Health Service: understanding difficulties and developments. Soc Sci Med 2006;63(9):2289-2300.

8. Vázquez, ML, Silva MRF, Campos ES, Arruda IKG, Diniz AS, Veras IL. et al. Participação social nos serviços de saúde: concepções dos usuários e líderes comunitários em dois municípios do Nordeste do Brasil. Cad. saúde pública 2003;19(2):579-591 2003.

9. Habermas J. Teoria de la acción comunicativa. Madrid: Taurus; 1987.

10. Reese-Schäfer W. Compreender Habermas. 2.ed. Petrópolis: Editora Vozes; 2009.

11. Bógus CM. Participação popular em saúde: formação política e desenvolvimento. São Paulo: Annablume: FAPESP; 1998.

12. Craco PF. Ação comunicativa no cuidado à saúde da família: encontros e desencontros entre profissionais de saúde e usuários. Ribeirão Preto. Tese [Doutorado em Enfermagem] -Escola de Enfermagem de Ribeirão Preto da
Universidade de São Paulo; 2006.

13. Franco TB, Merhy EE. Programa de Saúde da Família (PSF): contradições de um programa destinado à mudança do modelo tecnoassistencial. In: Merhy EE, Magalhães Júnior EM, Rimoli J, Franco TB, Bueno WS, organizadores. Trabalho em saúde: olhando e experienciando o SUS no cotidiano. 4 ed. São Paulo: Hucitec; 2003. p. 55-124.

14. Freitag B, Rouanet SP. Habermas. 3 ed. São Paulo: Ática; 1980.

15. Frederico P. A participação popular nas comissões locais de saúde: mostrando vidas, contando lutas. Ribeirão Preto. Dissertação [Mestrado em Enfermagem] -Escola de Enfermagem de Ribeirão Preto da Universidade de São Paulo; 2001.

16. Ayres JRCM. Sujeito, intersubjetividade e práticas de saúde. Ciênc Saúde Coletiva 2001;6(1):63-72.

17. Rivera FJU, Artmann E. Planejamento e gestão em saúde: flexibilidade metodológica e agir comunicativo. In: Rivera FJU. Análise estratégica em saúde e gestão pela escuta. Rio de Janeiro, FIOCRUZ; 2003. p. 17-35.

18. Ceccim RB, Feuerwerker LCM. O quadrilátero da formação para a área da saúde: ensino, gestão, atenção e controle social. Physis (Rio J) 2004;14(1):41-65. 